\title{
Adefovir dipivoxil is less expensive than lamivudine and associated with similar prognosis in patients with hepatitis B virus-related hepatocellular carcinoma after radical resection
}

\author{
This article was published in the following Dove Press journal: \\ OncoTargets and Therapy \\ 10 November 2016 \\ Number of times this article has been viewed
}

\author{
Jian-Hong Zhongl,* \\ Yang $\mathrm{Ke}^{1,2, *}$ \\ Shao-Liang Zhu',* \\ Lin Wang ${ }^{2}$ \\ Cheng-Piao Luo ${ }^{3}$ \\ Wen-Feng Gong' \\ Xue-Mei You' \\ Liang $\mathrm{Ma}^{\prime}$ \\ Bang-De Xiang' \\ Le-Qun $\mathrm{Li}^{\prime}$
}

'Department of Hepatobiliary Surgery, Affiliated Tumor Hospital of Guangxi Medical University, Nanning, ${ }^{2}$ Department of Hepatobiliary Surgery, The Second Affiliated Hospital of Kunming Medical University, Kunming, ${ }^{3}$ Department of Pathology, Affiliated Tumor Hospital of Guangxi Medical University, Nanning, People's Republic of China

*These authors contributed equally to this work
Aim: Lamivudine (LAM) and adefovir dipivoxil (ADV) are widely used in patients with hepatitis B virus (HBV)-related hepatocellular carcinoma (HCC), but few studies have directly compared their therapeutic efficacy and treatment cost. This study aims to compare LAM with ADV head-to-head in these patients.

Methods: We retrospectively analyzed 201 patients with HBV-related HCC who underwent radical resection and subsequently received LAM $(n=155)$ or ADV $(n=46)$. The two groups were compared in terms of HBV-DNA levels, liver function, antiviral resistance, recurrencefree, and overall survival, as well as antiviral medication costs.

Results: Despite significant improvement in HBV-DNA and alanine aminotransferase level in the LAM group after 1 year of antiviral therapy, these parameters did not differ significantly between the two groups over the following 2 years. Incidence of antiviral resistance after 1, 2, and 3 years of antiviral treatment was significantly higher in the LAM group $(19.5 \%, 45.7 \%$, and $56.4 \%)$ than in the ADV group $(0 \%, 3.3 \%$, and $14.5 \% ; P<0.001)$. Overall survival at 1,2 , and 3 years after resection was similar for the LAM group $(84.5 \%, 69.3 \%$, and $64.6 \%)$ and the ADV group $(84.1 \%, 77.8 \%$, and $63.4 \% ; P=0.905)$. Recurrence-free survival at the three follow-up points was also similar for the LAM group $(71.7 \%, 58.3 \%$, and $43.9 \%)$ and the ADV group $(81.1 \%, 66.1 \%$, and $53.0 \% ; P=0.452)$. Cox regression analysis confirmed that both nucleos $(\mathrm{t})$ ide analogues were associated with similar overall and recurrence-free survival. However, the average medication costs after 1,2 , and 3 years of antiviral treatment were significantly higher in the LAM group ( $€ 3.0, € 4.8$, and $€ 5.6$ per person per day) than in the ADV group (€2.2, €2.4, and $€ 3.1$ per person per day; all $P<0.05$ ).

Conclusion: ADV and LAM are associated with similar survival benefit in patients with HBV-related HCC after radical resection, but ADV is more cost-effective.

Keywords: adefovir dipivoxil, hepatitis B virus, hepatocellular carcinoma, lamivudine, radical resection

\section{Introduction}

Bang-De Xiang

Department of Hepatobiliary Surgery,

Affiliated Tumor Hospital of Guangxi

Medical University, He Di Road \#7I,

Nanning 53002I, People's Republic

of China

Tel +867715330986

Fax +86 77I 53I 2000

Email xitongpingjia@163.com;

xiangbangde@gmail.com
Hepatocellular carcinoma (HCC) is the sixth most common cancer and the third most frequent cause of cancer-related death in the world. ${ }^{1}$ Hepatic resection is widely recognized as a first-line treatment for patients with HCC. ${ }^{2,3}$ Nevertheless, the prognosis for patients after radical resection is discouraging, even when the disease is caught in an early stage: disease recurrence occurs in $>70 \%$ of patients within 5 years after resection. ${ }^{4,5}$ 
In East Asia and sub-Saharan Africa, where nearly $80 \%$ $\mathrm{HCC}$ cases arise, the major risk factor for this disease is chronic hepatitis B virus (HBV) infection. ${ }^{1}$ Five oral antiHBV agents, all nucleos(t)ide analogues, are widely used in the clinic: lamivudine (LAM), adefovir dipivoxil (ADV), entecavir, telbivudine, and tenofovir disoproxil fumarate. Two randomized controlled trials, ${ }^{6,7}$ a nationwide cohort study $^{8}$ and two systematic reviews, ${ }^{9,10}$ have shown that these analogues increase overall and recurrence-free survival in some patients with HBV-related HCC after radical resection. However, these findings are based on comparisons with placebo or no treatment, leaving open the question of how the analogues compare with one another.

Apart from one retrospective study comparing LAM and entecavir in a small sample cohort of patients, ${ }^{11}$ no head-tohead drug comparison for patients with HBV-related HCC has been published to our knowledge. This is an important question because of economics, especially in resourcerestricted settings: if one analogue is associated with much lower treatment costs than another but the two drugs show comparable therapeutic efficacy, then the less expensive one may be preferable.

LAM and ADV are the most widely used nucleos(t)ide analogues in developing countries because they are much less expensive than novel analogues such as entecavir and tenofovir disoproxil fumarate, yet they show satisfactory antiviral efficacy. Therefore, we decided to directly compare LAM and ADV to identify the one associated with greater benefit and lower cost in patients with HBV-related HCC after radical resection. We took into account several outcomes, including HBV-DNA levels, liver function, antiviral resistance, recurrence-free, and overall survival, as well as antiviral medication cost.

\section{Materials and methods}

Our study protocol was approved by the Ethics Committee of the Affiliated Tumor Hospital of Guangxi Medical University, and all participants were volunteers who gave written informed consent.

\section{Patients}

This study was conducted by retrospectively reviewing medical records entered prospectively into the central database of The Affiliated Tumor Hospital of Guangxi Medical University from January 2007 to December 2013. During this period, a total of 1,569 patients with $\mathrm{HCC}$ were recorded in the database.

To be included in this study, patients had to satisfy the following inclusion criteria: 1) initial radical resection for
HCC was performed in the Affiliated Tumor Hospital of Guangxi Medical University, and diagnosis was verified by postoperative pathology; 2) the test for serum hepatitis B surface antigen (HBsAg) was positive; 3 ) the patient was in Barcelona Clinic Liver Cancer stage 0 or A; 4) the patient showed good liver function (Child-Pugh A); and 5) the patient received either $\mathrm{LAM}$ or $\mathrm{ADV}$ as initial antiviral treatment after operation.

Patients were excluded from the study if they: 1) had received antitumor therapy before resection, such as transarterial chemoembolization; 2) had received antiviral therapy before resection; 3 ) were infected with hepatitis $\mathrm{C}$ or $\mathrm{D}$ virus or human immunodeficiency virus in addition to HBV; 4) suffered from other malignant tumors or serious medical illness, including myocardial infarction, cerebrovascular event, or transient ischemic attack; 5) had a history of alcoholism or drug abuse; or 6) were subsequently transferred to another hospital or otherwise lost to follow-up.

\section{Surgical procedure}

All patients underwent radical resection for $\mathrm{HCC}$, defined as a complete resection of all macroscopic tumors, absence of tumor cells along the parenchymal transection line (confirmed by postoperative pathology), and no residual tumor detected in the remnant liver by dynamic computed tomography 3-4 weeks after surgery. ${ }^{6,7,12,13}$ Surgery was performed through a reverse L-shaped incision. We carefully searched the abdominal cavity to assess the extent of local lesions and extrahepatic metastases. If necessary, intraoperative ultrasonography was used to identify the size and number of tumors, as well as identify the position of tumor margins relative to the hepatic vasculature. Pringle's maneuver was applied to occlude the blood inflow of the liver with cycles of clamping (15 min) and no clamping (5 min). Liver resection was carried out using a clamp-crushing method. ${ }^{14,15}$

\section{Antiviral treatment}

After radical resection, patients were administered LAM (100 mg per day; GlaxoSmithKline [China] Investment Co. Ltd.) or ADV (10 mg per day; GlaxoSmithKline [China] Investment Co. Ltd.) within 1 week after surgery, in accord with chronic hepatitis B guidelines from 2007 of the American Association for the Study of Liver Disease. ${ }^{16}$ Routine practice at our medical center is to recommended indefinite continuation of antiviral treatment unless toxicity is unacceptable or patient withdraws consent. This practice is motivated by the fact that nucleos(t)ide analogues therapy cannot completely eradicate $\mathrm{HBV}$ due to the persistence of covalently closed circular DNA in the nuclei of infected 
hepatocytes, ${ }^{7,17}$ which serves as a template for further HBV replication. In addition, viral relapse after nucleos(t)ide analogues therapy occurs frequently, even if HBV-DNA has been undetectable by polymerase chain reaction (PCR) for $>1$ year. ${ }^{18}$

\section{Follow-up and assessment of outcomes}

All patients were followed up once monthly at outpatient or inpatient departments in the first year after radical resection, and then once every 2-3 months. Each follow-up visit involved tests of HBV serology, HBV-DNA levels, liver function, alpha-fetoprotein (AFP) levels, and imaging tests, including chest radiography, abdominal ultrasonography, dynamic computed tomography, or magnetic resonance imaging. HBV-DNA was quantified by PCR assay (Amplicor HBV Monitor assay, Roche Diagnostics, Mannheim, Germany), for which the lower limit was $2.6 \log _{10} \mathrm{IU} / \mathrm{mL}$. Follow-up was continued through December 2015, when all surviving patients had been followed for at least 36 months.

Both recurrence-free and overall survival were the main outcomes. Postoperative recurrence, either intra- or extrahepatic recurrence, was confirmed when lesions with characteristic features of HCC were observed using any two of the following imaging methods: ultrasonography, dynamic computed tomography, or magnetic resonance imaging. ${ }^{19}$

Secondary outcomes included HBV-DNA levels, liver function, antiviral resistance, and the cost of antiviral therapy. Antiviral resistance was diagnosed based on HBV virological breakthrough and in some patients subsequent biochemical breakthrough ${ }^{18} \mathrm{HBV}$ virological breakthrough was defined as an increase in HBV-DNA level of $>1 \log _{10} \mathrm{IU} / \mathrm{mL}$ above the lowest level measured up to that point during treatment. ${ }^{16,18}$ Biochemical breakthrough due to HBV virological breakthrough was defined as an increase in levels of serum alanine aminotransferase (ALT) above the upper normal limit after achieving normalization during treatment in the absence of medication noncompliance, clinical features of tumor progression, hepatotoxic drugs, treatment-related hepatic damage, or other systemic infections. ${ }^{16,18}$ Genotypic and phenotypic data on resistant HBV in our patients were unavailable, which otherwise provide a more precise way to measure antiviral resistance. ${ }^{16,18}$ Patients who developed antiviral resistance were switched from LAM or ADV to entecavir (1.0 mg per day; Sino-American Shanghai Squibb Pharmaceuticals Ltd.). ${ }^{16,18}$

We calculated the average medication cost for LAM group first by counting the number of patients who developed antiviral resistance and the number of patients who did not at the end of the given year. Then we multiplied each number by the per-person-per-day (PPPD) price, respectively, of entecavir or LAM. Next, we divided these total numbers by the number of people who survived in each group at the end of that year. We calculated the treatment cost in the ADV group similar to the way we calculated the cost in the LAM group. We reported average medication costs as PPPD due to variable follow-up periods. The following medication prices were taken directly from the central database of the Affiliated Tumor Hospital of Guangxi Medical University and were in accordance with the Nanning Municipal Bureau of Pricing: LAM, $100 \mathrm{mg}, 14$ tablets, €23.6; ADV, $10 \mathrm{mg}$, 14 tablets, €30.8; and entecavir, $0.5 \mathrm{mg}, 7$ tablets, €29.9 $\left(1 \mathrm{CNY}=0.1287\right.$ EUR, September 2014). ${ }^{20}$

\section{Statistical analysis}

To reduce selection and confounding bias arising from baseline differences between the LAM and ADV groups, we used propensity score matching. ${ }^{21}$ We generated a logistic regression model to estimate the probability of each patient receiving ADV treatment on the basis of 15 pretreatment (baseline) variables. Patients were grouped together with a 0.2 caliper width in order to match each ADV patient with up to two LAM patients (1:2 match). To ensure that propensity score matching was feasible in our cohort, we generated a box plot to determine whether the two groups showed sufficient overlap (common support region) in their propensity scores (not shown). To assess the balance in the matched cohort, we calculated standardized differences and defined a difference of $<10 \%$ as indicating good balance.

Data were analyzed using SPSS 19.0 (IBM, Chicago, IL, USA). Quantitative variables were reported as mean \pm SD or median (range) and compared using, respectively, Student's $t$-test or the Mann-Whitney nonparametric $U$-test. Categorical variables were compared using the $\chi^{2}$ test. Survival rate and cumulative antiviral resistance rate were estimated using the Kaplan-Meier method, and differences between groups were compared using the log-rank test. A Cox proportional hazard model was used to generate hazard ratio (HRs) and corresponding 95\% confident intervals (CIs) to predict overall and recurrence-free survival as a function of baseline variables. Differences were considered significant when $P<0.05$.

\section{Results}

\section{Study population}

A total of 201 patients were included in the study, comprising 155 patients (77.1\%) who received LAM treatment and 46 (22.9\%) who received ADV treatment after radical resection (Figure 1). The median follow-up period was 21.0 months 




Figure I Flow diagram of study population selection.

Abbreviations: ADV, adefovir dipivoxil; HBsAg, hepatitis B surface antigen; HCC, hepatocellular carcinoma; HIV, human immunodeficiency virus; LAM, lamivudine; $\mathrm{PEI}$, percutaneous ethanol injection; RFA, radiofrequency ablation; TACE, transarterial chemoembolization.

(range, 1.0-80.0). Baseline characteristics of the complete LAM and ADV groups before propensity score matching are shown in Table 1. Standardized differences were at least $10 \%$ for the following 10 baseline variables: age, gender, HBV-DNA level, HBeAg status, albumin level, ALT level, liver cirrhosis, diabetes mellitus, tumor size, and presence of satellite nodules. LAM patients had significantly higher levels of HBV-DNA $(P<0.001)$ and they tended to have slightly higher levels of ALT $(P=0.065)$. Conversely, ADV patients had significantly more satellite nodules $(P=0.011)$.

Propensity score matching yielded 38 matched pairs comprising $38 \mathrm{ADV}$ patients and $68 \mathrm{LAM}$ patients (this was

Table I Baseline characteristics of the study population before propensity score matching

\begin{tabular}{|c|c|c|c|c|}
\hline Variable & $\begin{array}{l}\text { LAM group } \\
(n=155)\end{array}$ & $\begin{array}{l}\text { ADV group } \\
(n=46)\end{array}$ & $\begin{array}{l}\text { Standardized } \\
\text { difference (\%) }\end{array}$ & $P$-value \\
\hline Age, year & $48.6 \pm 9.8$ & $49.8 \pm 10.5$ & 11.5 & 0.472 \\
\hline Gender, male/female (\%) & $145(93.5) / 10(6.5)$ & $40(87.0) / 6(13.0)$ & 19.4 & 0.254 \\
\hline HBV-DNA $\left(\log _{10} 1 \mathrm{I} / \mathrm{mL}\right)$ & $5.3(2.7-9.3)$ & $4.7(2.7-6.7)$ & 91.5 & $<0.001$ \\
\hline $\mathrm{HBeAg},+/-(\%)$ & $28(18.1) / 127(81.9)$ & $4(8.7) / 42(91.3)$ & 32.9 & 0.127 \\
\hline Total bilirubin $(\mu \mathrm{mol} / \mathrm{L})$ & $13.8 \pm 7.4$ & $13.9 \pm 7.0$ & 1.2 & 0.944 \\
\hline Albumin $(g / L)$ & $40.2 \pm 4.4$ & $41.4 \pm 4.2$ & 28.3 & 0.11 \\
\hline Alanine aminotransferase (IU/L) & $41.0(8.0-504.0)$ & $34.5(5.0-1 \mid 8.0)$ & 42.9 & 0.065 \\
\hline Prothrombin time (s) & $12.9 \pm 1.4$ & $12.9 \pm 1.2$ & 1.0 & 0.96 \\
\hline$\alpha$-Fetoprotein, $\geq 400 \mathrm{ng} / \mathrm{mL} /<400 \mathrm{ng} / \mathrm{mL}(\%)$ & $46(29.7) / 109(70.3)$ & $13(28.3) / 33(7 \mid .7)$ & 3.1 & 0.853 \\
\hline Liver cirrhosis, present/absent (\%) & | $34(86.5) / 2$ | (I3.5) & $38(82.6) / 8(17.4)$ & 10.0 & 0.515 \\
\hline Gastroesophageal varices, present/absent (\%) & $27(17.4) / / 28(82.6)$ & $7(15.2) / 39(84.8)$ & 6.1 & 0.726 \\
\hline Diabetes mellitus, present/absent (\%) & $10(6.5) / 145(93.5)$ & $6(13.0) / 40(87.0)$ & 19.4 & 0.254 \\
\hline Tumor size $(\mathrm{cm})$ & $5.0(0.8-18.0)$ & $4.0(2.0-10.2)$ & 54.1 & 0.102 \\
\hline Satellite nodule, present/absent (\%) & $32(20.6) / / 23(79.4)$ & $18(39.1) / 28(60.9)$ & 37.5 & 0.011 \\
\hline Microvascular infiltration, present/absent (\%) & $19(12.3) / / 36(87.7)$ & $7(15.2) / 39(84.8)$ & 8.1 & 0.599 \\
\hline
\end{tabular}

Note: Variables are expressed as mean \pm standard deviation, as median (range), or as $\mathrm{n}(\%)$.

Abbreviations: ADV, adefovir dipivoxil; HBeAg, hepatitis B e antigen; LAM, lamivudine; s, seconds; HBV, hepatitis B virus; +/-, positive/negative. 
Table 2 Baseline characteristics of the study population after propensity score matching

\begin{tabular}{|c|c|c|c|c|}
\hline Variable & $\begin{array}{l}\text { LAM group } \\
(n=68)\end{array}$ & $\begin{array}{l}\text { ADV group } \\
(n=38)\end{array}$ & $\begin{array}{l}\text { Standardized } \\
\text { difference (\%) }\end{array}$ & $P$-value \\
\hline Age (year) & $49.0 \pm 9.7$ & $49.8 \pm 9.9$ & 2.5 & 0.691 \\
\hline Gender, male/female (\%) & $62(91.2) / 6(8.8)$ & $36(94.7) / 2(5.3)$ & 7.5 & 0.778 \\
\hline HBV-DNA $\left(\log _{10} 1 \mathrm{IU} / \mathrm{mL}\right)$ & $5.2(2.7-6.0)$ & $4.7(2.7-5.7)$ & 2.7 & 0.364 \\
\hline $\mathrm{HBeAg},+/-(\%)$ & $7(\mid 0.3) / 6 \mid(89.7)$ & $3(7.9) / 35(92.1)$ & 4.6 & 0.953 \\
\hline Total bilirubin $(\mu \mathrm{mol} / \mathrm{L})$ & $13.8 \pm 9.0$ & $14.0 \pm 7.5$ & 2.3 & 0.940 \\
\hline Albumin (g/L) & $41.2 \pm 4.4$ & $41.3 \pm 4.3$ & 1.4 & 0.922 \\
\hline Alanine aminotransferase (IU/L) & $37.5(8.0-192.0)$ & $36.5(5.0-109.0)$ & 4.3 & 0.575 \\
\hline Prothrombin time (s) & $12.9 \pm 1.5$ & $\mid 3.0 \pm 1.1$ & 2.8 & 0.875 \\
\hline$\alpha$-Fetoprotein, $\geq 400 \mathrm{ng} / \mathrm{mL} /<400 \mathrm{ng} / \mathrm{mL}(\%)$ & $19(27.9) / 49(72.1)$ & II (28.9)/27 (78.I) & 2.9 & 0.912 \\
\hline Liver cirrhosis, present/absent (\%) & $56(82.4) / 12(17.6)$ & $30(78.9) / 8(21.1)$ & 2.3 & 0.667 \\
\hline Gastroesophageal varices, present/absent (\%) & II (16.2)/57 (83.8) & $6(15.8) / 32(84.2)$ & 3.6 & 0.958 \\
\hline Diabetes mellitus, present/absent (\%) & $7(10.3) / 61(89.7)$ & $4(10.5) / 34(89.5)$ & 3.9 & 1.000 \\
\hline Tumor size $(\mathrm{cm})$ & $4.2(0.8-12.6)$ & $4.0(2.0-10.2)$ & 8.5 & 0.673 \\
\hline Satellite nodule, present/absent (\%) & $16(23.5) / 52(76.5)$ & $10(26.3) / 28(73.7)$ & 5.3 & 0.749 \\
\hline Microvascular infiltration, present/absent (\%) & $9(13.2) / 59(86.8)$ & $4(10.5) / 34(89.5)$ & 7.2 & 0.921 \\
\hline
\end{tabular}

Note: Variables are expressed as mean \pm standard deviation, as median (range), or as $\mathrm{n}(\%)$.

Abbreviations: ADV, adefovir dipivoxil; $\mathrm{HBeAg}$, hepatitis B e antigen; LAM, lamivudine; HBV, hepatitis B virus; +/-, positive/negative.

not perfect 1:2 matching due to the effects of the 0.2 caliper width). Propensity score-matched pairs showed no significant differences in terms of baseline characteristics, meaning that all standardized differences were below $10 \%$ and all $P>0.05$ (Table 2).

\section{HBV-DNA levels and liver function in propensity score-matched patients}

HBV-DNA levels and liver function in propensity scorematched patients are presented in Table 3. Median LAM treatment duration was 25.5 months (range, 5.0-54.0), similar

Table 3 Serial changes in HBV-DNA levels and liver function for propensity score-matched patients

\begin{tabular}{|c|c|c|c|}
\hline Variable & LAM group & ADV group & $P$-value \\
\hline \multicolumn{4}{|l|}{ HBV-DNA $\left(\log _{10} 1 \mathrm{IU} / \mathrm{mL}\right)$} \\
\hline Baseline & $5.2(2.7-6.0)$ & $4.7(2.7-5.7)$ & 0.364 \\
\hline I year after resection & $2.7(1.4-4.7)$ & $3.0(2.1-4.7)$ & 0.012 \\
\hline 2 years after resection & $2.4(1.8-4.1)$ & $2.7(1.2-3.8)$ & 0.876 \\
\hline 3 years after resection & $2.1(1.0-3.6)$ & $2.3(I . I-2.7)$ & 0.180 \\
\hline \multicolumn{4}{|l|}{ Total bilirubin $(\mu \mathrm{mol} / \mathrm{L})$} \\
\hline Baseline & $13.8 \pm 9.0$ & $14.0 \pm 7.5$ & 0.940 \\
\hline I year after resection & $13.0 \pm 8.0$ & $|4| \pm 5.4$. & 0.706 \\
\hline 2 years after resection & $13.9 \pm 8.5$ & $13.9 \pm 7.9$ & 0.598 \\
\hline 3 years after resection & 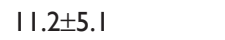 & $|3.4 \pm 4|$. & 0.335 \\
\hline \multicolumn{4}{|l|}{ Albumin (g/L) } \\
\hline Baseline & $41.2 \pm 4.4$ & $41.3 \pm 4.3$ & 0.922 \\
\hline I year after resection & $43.4 \pm 4.0$ & $43.0 \pm 5.0$ & 0.720 \\
\hline 2 years after resection & $43.0 \pm 4.6$ & $45.4 \pm 4.3$ & 0.133 \\
\hline 3 years after resection & $42.5 \pm 4.3$ & $42.5 \pm 6.4$ & 0.999 \\
\hline \multicolumn{4}{|c|}{ Alanine aminotransferase (IU/L) } \\
\hline Baseline & $37.5(8.0-192.0)$ & $36.5(5.0-109.0)$ & 0.575 \\
\hline I year after resection & $30.0(12.0-158.0)$ & $34.0(13.0-82.0)$ & 0.002 \\
\hline 2 years after resection & $22.0(11.0-103.0)$ & $28.0(16.0-78.0)$ & 0.325 \\
\hline 3 years after resection & $26.0(6.0-159.0)$ & $29.0(21.0-137.0)$ & 0.680 \\
\hline \multicolumn{4}{|l|}{ Prothrombin time (s) } \\
\hline Baseline & $12.9 \pm 1.5$ & $|3.0 \pm| . \mid$ & 0.875 \\
\hline I year after resection & $13.3 \pm 1.4$ & $13.3 \pm 1.5$ & 0.863 \\
\hline 2 years after resection & $13.1 \pm 1.3$ & $13.4 \pm 1.6$ & 0.539 \\
\hline 3 years after resection & $13.0 \pm 1.2$ & $13.2 \pm 1.5$ & 0.764 \\
\hline
\end{tabular}

Note: Variables are expressed as mean \pm standard deviation or as median (range).

Abbreviations: ADV, adefovir dipivoxil; LAM, lamivudine; HBV, hepatitis B virus; s, seconds. 
to the median ADV treatment duration of 21.5 months (range, 6.0-63.0; $P=0.293$ ). Levels of HBV DNA after 1 year of antiviral therapy were significantly lower in the LAM group than in the ADV group $(P=0.012)$, though the levels were similar at 2 years $(P=0.876)$ and 3 years $(P=0.180)$. Similarly, ALT level was significant lower in the LAM group at 1 year $(P=0.002)$, but the levels were similar between the two groups at 2 years $(P=0.325)$ and 3 years $(P=0.680)$. Other liver function parameters, including total bilirubin, albumin, and prothrombin time, were similar between the two groups after 1, 2, and 3 years of antiviral therapy (all $P>0.05$ ).

\section{Antiviral resistance in propensity score-matched patients}

During antiviral treatment, 27 patients in the LAM group (39.7\%) showed HBV virological breakthrough. Of these, $13(48.1 \%)$ maintained stable liver function, while the other 14 (51.9\%) exhibited biochemical breakthrough. In the ADV group, only four patients (10.5\%) suffered HBV virological breakthrough, of whom two showed biochemical breakthrough. The breakthrough was successfully controlled in all antiviral-resistant patients by switching them from LAM or ADV to entecavir, and none of these patients suffered decompensation or decompensation-related mortality. Altogether the incidence of antiviral resistance after 1, 2 and 3 years of antiviral treatment was $19.5 \%, 45.7 \%$, and $56.4 \%$ in the LAM group and $0 \%, 3.3 \%$, and $14.5 \%$ in the ADV group, respectively $(P<0.001$, Figure 2$)$.

\section{Anti-HBV medication costs in propensity score-matched patients}

Figure 3 shows the average anti-HBV medication costs in the propensity score-matched patients. At the beginning of

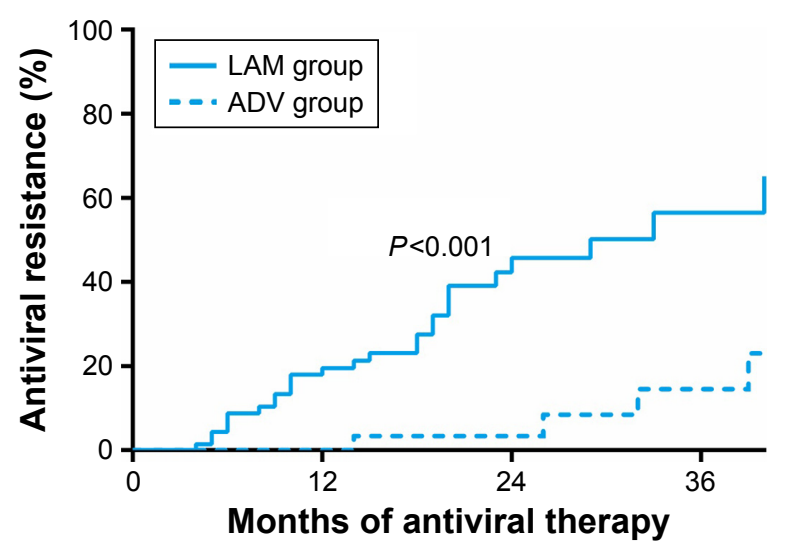

Figure 2 Comparison of cumulative antiviral resistance during LAM or ADV treatment in propensity score-matched patients with HBV-related HCC after radical resection.

Abbreviations: ADV, adefovir dipivoxil; LAM, lamivudine; HCC, hepatocellular carcinoma; HBV, hepatitis B virus.

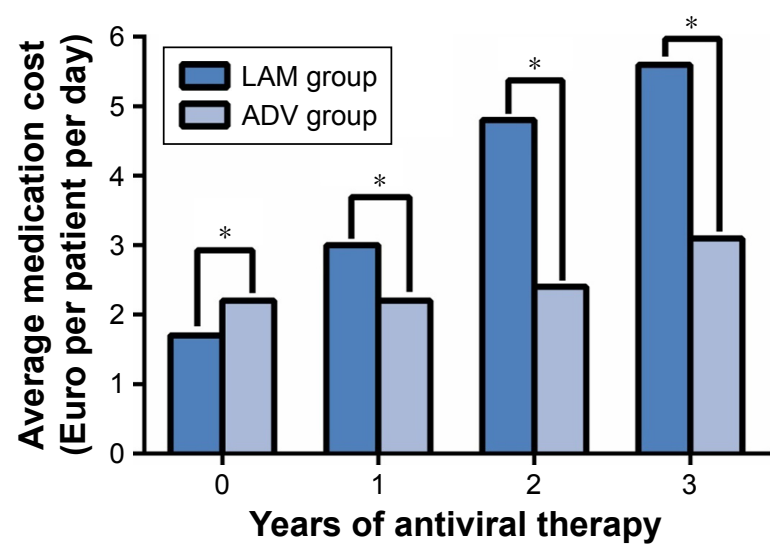

Figure 3 Average anti-HBV medication costs in LAM and ADV groups at the end of $0,1,2$, and 3 years of antiviral therapy.

Notes: Data were reported as per-patient-per-day due to variable follow-up periods. $* P<0.05$, LAM versus ADV groups.

Abbreviations: ADV, adefovir dipivoxil; LAM, lamivudine; HBV, hepatitis B virus.

oral antiviral therapy, the average medication costs were significantly lower in the LAM group than in the ADV group because of the higher unit price of ADV ( $€ 1.7$ PPPD for LAM vs $€ 2.2$ PPPD for ADV, $P<0.001)$. However, the average medication costs were significantly higher in the LAM group than in the ADV group at 2 years $(P<0.001)$ and 3 years $(P=0.001)$ as a result of fact that 27 of 68 LAM patients (39.7\%) suffered antiviral resistance and were switched to more expensive entecavir treatment, costing €8.5 PPPD, compared to only 4 of $38 \mathrm{ADV}$ patients $(10.5 \% ; P<0.001)$. The average medication cost of the LAM group was $€ 3.0$ at the end of 1 year, $€ 4.8$ at the end of 2 years, and $€ 5.6$ PPPD at 3 years; the corresponding costs for the ADV group were $€ 2.2, € 2.4$ and $€ 3.1$ PPPD.

\section{Overall and recurrence-free survival in the complete cohort and propensity score-matched patients}

Overall survival in the complete cohort at 1,2, and 3 years was similar for the LAM group $(85.7 \%, 73.5 \%$, and $62.7 \%)$ and the ADV group $(82.6 \%, 74.8 \%$, and $63.7 \% ; P=0.912$; Figure 4A). Similarly, recurrence-free survival at 1,2 , and 3 years was similar for the LAM group $(69.2 \%, 56.4 \%$, and $42.4 \%)$ and the ADV group $(76.5 \%, 64.0 \%$, and $53.5 \%$; $P=0.346$; Figure 4B).

Similar results were obtained with propensity scorematched patients. In the matched cohort, overall survival at 1,2 , and 3 years was similar for the LAM group (84.5\%, $69.3 \%$, and $64.6 \%)$ and the ADV group (84.1\%, 77.8\%, and $63.4 \% ; P=0.905$; Figure 4C). Recurrence-free survival at the three follow-up points was similar for the LAM group 

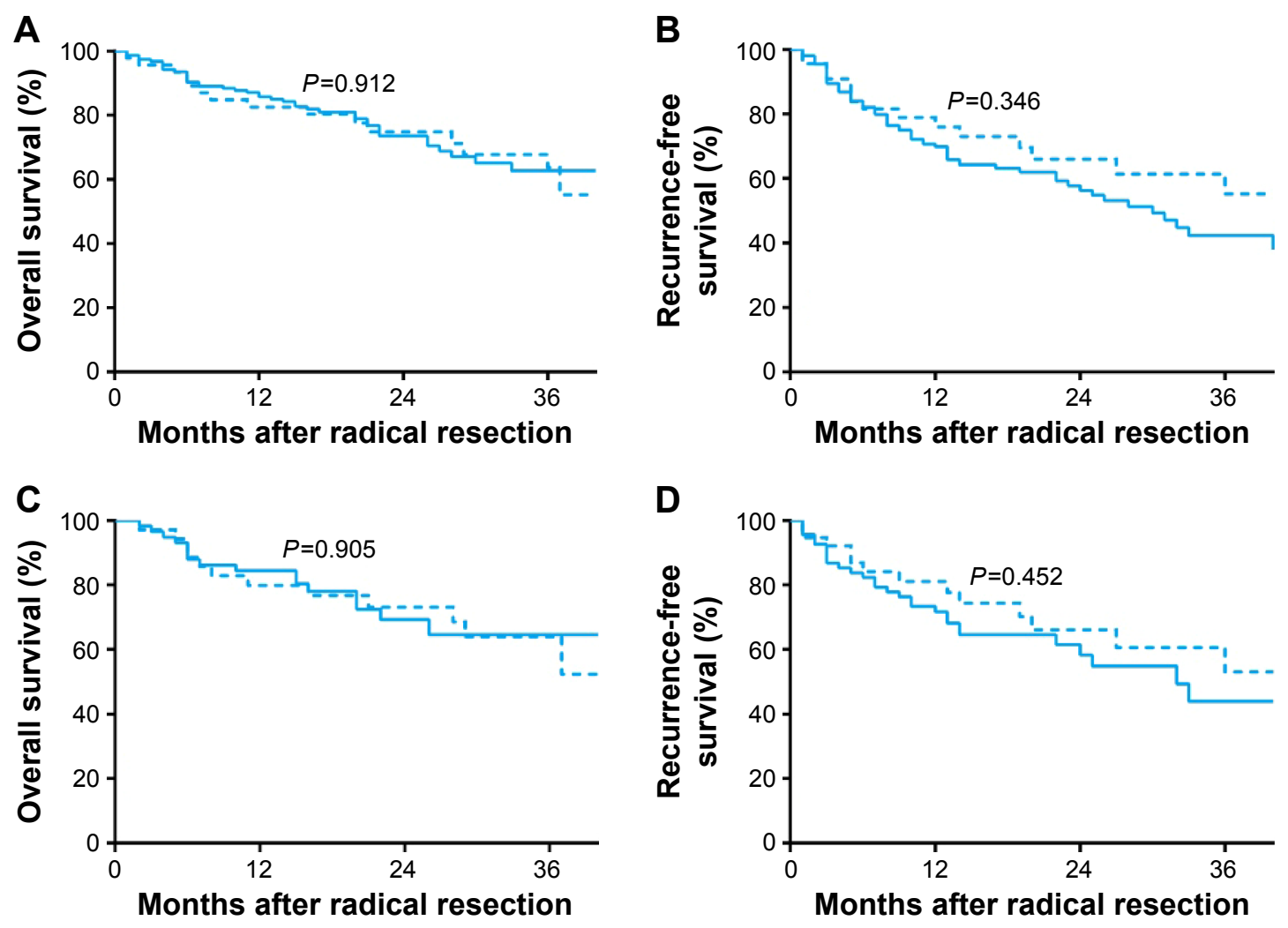

Figure 4 Survival curves of patients in the LAM and ADV groups.

Notes: (A) Overall survival and (B) recurrence-free survival between the LAM and ADV groups before propensity score matching. (C) Overall survival and (D) recurrencefree survival between the LAM and ADV groups after propensity score matching.

Abbreviations: ADV, adefovir dipivoxil; LAM, lamivudine.

$(71.7 \%, 58.3 \%$, and $43.9 \%)$ and the ADV group $(81.1 \%$, $66.1 \%$, and $53.0 \% ; P=0.452$; Figure 4D).

\section{Baseline factors predictive of overall and recurrence-free survival}

To identify whether any of the 15 pretreatment variables predicted overall or recurrence-free survival in our cohort, we performed Cox regression (Table 4). The analysis identified the following independent risk factors of overall survival: age $\geq 60$ years (HR 2.738, 95\% CI 1.373 to $5.459, P=0.004$ ), HBV-DNA level $\geq 5.3 \log _{10} \mathrm{IU} / \mathrm{mL}$ (HR 2.716, 95\% CI 1.259 to $5.860, P=0.011$ ) and tumor size $\geq 10 \mathrm{~cm}$ (HR 2.601, 95\% CI 1.189 to $5.689, P=0.017)$. The corresponding Cox regression for recurrence-free survival identified the presence of satellite nodules as an independent risk factor (HR 2.328, 95\% CI 1.346 to $4.029, P=0.003$ ) and liver cirrhosis as an independent protective factor (HR $0.511,95 \%$ CI 0.273 to $0.958, P=0.036)$.

When the type of antiviral treatment (LAM or ADV) was assessed for its ability to predict overall or recurrence-free survival, the HR was not significantly different from 1 (HR 1.370, 95\% CI 0.678 to $2.770, P=0.380$ for overall survival; HR 0.779 , 95\% CI 0.434 to $1.396, P=0.401$ for recurrence-free survival), consistent with the similar survival rates between two groups for both the complete cohort and the propensity score-matched patients.

\section{Discussion}

Numerous studies indicate that nucleos(t)ide analogues therapy not only suppresses HBV replication and protects liver function ${ }^{6,12,19,22-26}$ but also increases overall and recurrencefree survival in patients with HBV-related HCC. ${ }^{6-8,13,27-31}$ While this body of evidence has helped drive the widespread use of nucleos(t)ide analogues in HBV-related HCC patients, it does not help clinicians decide between alternative analogues when particular drugs are contraindicated or when the cost of a drug becomes prohibitive. This highlights the need for head-to-head comparisons of neocleos(t)ide analogues, particularly in resource-limited settings. Our results with antiviral therapy-naïve patients with $\mathrm{HBV}$-related $\mathrm{HCC}$ after 
Table 4 Cox regression analysis of baseline factors predictive of overall and recurrence-free survival

\begin{tabular}{|c|c|c|c|c|c|c|}
\hline \multirow[t]{2}{*}{ Variable } & \multicolumn{3}{|c|}{ Risk of poor overall survival } & \multicolumn{3}{|c|}{ Risk of poor recurrence-free survival } \\
\hline & $\begin{array}{l}\text { Hazard } \\
\text { ratio }\end{array}$ & $\begin{array}{l}95 \% \text { confidence } \\
\text { interval }\end{array}$ & $P$-value & $\begin{array}{l}\text { Hazard } \\
\text { ratio }\end{array}$ & $\begin{array}{l}95 \% \text { confidence } \\
\text { interval }\end{array}$ & $P$-value \\
\hline Age ( $\geq 60$ vs $<60$ years) & 2.738 & $1.373-5.459$ & 0.004 & 1.274 & $0.680-2.387$ & 0.449 \\
\hline Gender (male vs female) & 0.922 & $0.355-2.389$ & 0.867 & 2.743 & $0.833-9.032$ & 0.097 \\
\hline HBV-DNA $\left(\geq 5.3\right.$ vs $\left.<5.3 \log _{10} \mathrm{IU} / \mathrm{mL}\right)$ & 2.716 & $1.259-5.860$ & 0.011 & 1.717 & $0.869-3.390$ & 0.199 \\
\hline $\mathrm{HBeAg}(+\mathrm{vs}-)$ & 0.598 & $0.263-1.36 \mid$ & 0.220 & 0.824 & $0.423-1.605$ & 0.569 \\
\hline Total bilirubin ( $\geq 17.1 \mathrm{vs}<17.1 \mu \mathrm{mol} / \mathrm{L})$ & 1.215 & $0.657-2.246$ & 0.534 & 0.727 & $0.414-1.277$ & 0.267 \\
\hline Albumin ( $\geq 40$ vs $<40 \mathrm{~g} / \mathrm{L})$ & 1.430 & $0.787-2.597$ & 0.241 & 0.715 & $0.426-1.199$ & 0.203 \\
\hline Alanine aminotransferase ( $\geq 80$ vs $<80 \mathrm{IU} / \mathrm{L}$ ) & 1.435 & $0.644-3.196$ & 0.377 & 0.639 & $0.276-1.483$ & 0.298 \\
\hline Prothrombin time ( $\geq 14$ vs $<14 \mathrm{~s})$ & 1.103 & $0.550-2.211$ & 0.782 & 1.022 & $0.578-1.809$ & 0.939 \\
\hline$\alpha$-Fetoprotein ( $\geq 400$ vs $<400 \mathrm{ng} / \mathrm{mL}$ ) & 1.625 & $0.875-3.019$ & 0.124 & 0.943 & $0.545-1.63 \mid$ & 0.833 \\
\hline Liver cirrhosis (present vs absent) & 1.879 & $0.792-4.461$ & 0.153 & 0.511 & $0.273-0.958$ & 0.036 \\
\hline Gastroesophageal varices (present vs absent) & 0.970 & $0.453-2.081$ & 0.939 & 1.324 & $0.370-2.470$ & 0.377 \\
\hline Diabetes mellitus (present vs absent) & 1.214 & $0.493-2.988$ & 0.673 & 0.682 & $0.277-1.68 \mid$ & 0.406 \\
\hline Tumor size $(\geq 10 \mathrm{vs}<10 \mathrm{~cm})$ & 2.601 & I.189-5.689 & 0.017 & 0.981 & $0.440-2.189$ & 0.962 \\
\hline Satellite nodule (present vs absent) & $\mathrm{I} .382$ & $0.734-2.604$ & 0.317 & 2.328 & $1.346-4.029$ & 0.003 \\
\hline Microvascular infiltration (present vs absent) & $\mathrm{I} .344$ & $0.615-2.934$ & 0.459 & 0.642 & $0.280-1.474$ & 0.296 \\
\hline Antiviral therapy (ADV vs LAM) & 1.370 & $0.678-2.770$ & 0.380 & 0.779 & $0.434-1.396$ & 0.401 \\
\hline
\end{tabular}

Abbreviations: ADV, adefovir dipivoxil; $\mathrm{HBeAg}$, hepatitis B e antigen; LAM, lamivudine; $\mathrm{HBV}$, hepatitis $\mathrm{B}$ virus; s, seconds.

radical resection suggest that LAM and ADV are associated with similar overall and recurrence-free survival at up to 3 years, but that ADV strategy is associated with significantly lower antiviral medication costs.

In the absence of special guidelines about anti-HBV therapy for HBV-related HCC, doctors from different parts of the world prescribe nucleos $(\mathrm{t})$ ide analogues for such patients according to current chronic hepatitis B guidelines, ${ }^{18,32-36}$ most of which recommend entecavir and tenofovir disoproxil fumarate as first-line antiviral therapy in patients with chronic hepatitis B because of their superior ability to suppress viral replication and because of high genetic barriers to the development of resistance. However, these novel drugs are very expensive and unavailable in some countries; for example, tenofovir disoproxil fumarate became available in People's Republic of China only in 2014. Moreover, these guidelines ${ }^{18,32-36}$ were developed for patients whose major disease is chronic hepatitis $\mathrm{B}$, and it is unclear whether they are optimal for patients with HBV-related $\mathrm{HCC} .{ }^{10} \mathrm{~A}$ recent retrospective study ${ }^{11}$ with a small sample size reported that LAM and entecavir were associated with similar antiviral efficacy, incidence of antiviral resistance, and overall survival in patients in advanced stages of HBV-related HCC. This challenges the first-line status of entecavir.

We observed significantly lower levels of HBV-DNA and ALT in the LAM group than in the ADV group at 1 year after antiviral therapy. These results are similar to those of $\mathrm{He}$ et al, ${ }^{37}$ who investigated the relative clinical efficacy of LAM and ADV in patients with chronic HBV infection in a randomized controlled trial. He et $\mathrm{al}^{37}$ interpreted their findings as suggesting that ADV reduces HBV viral load more slowly than LAM. However, beyond 1 year, levels of HBV-DNA and ALT were similar between our two groups, and this reflects in part the obviously increasing emergence of antiviral assistance in our LAM patients with extended therapy, which may offset the superior antiviral effect of LAM over ADV during the initial therapy. This is supported by a meta-analysis ${ }^{38}$ evaluating the relative efficacy of oral antiviral therapies for chronic HBV infection. Other liver function parameters in our cohort did not differ significantly between the two groups at 1,2, or 3 years of antiviral treatment, which may reflect in part the fact that they are less sensitive indicators of hepatitis than ALT. ${ }^{14}$

In our cohort, the frequency of antiviral resistance was $19.5 \%$ at 1 year, $45.7 \%$ at 2 years, and $56.4 \%$ at 3 years in the LAM group, significantly higher than the corresponding frequencies of $0 \%, 3.3 \%$, and $14.5 \%$ in the ADV group. These values are consistent with previous studies with chronic HBV infection. ${ }^{39-42}$ These studies with chronic HBV infection ${ }^{39,40}$ reported frequencies of $17 \%-23 \%$ at 1 year, $40 \%-46 \%$ at 2 years, and $55 \%-57 \%$ at 3 years in the LAM group, higher than the corresponding frequencies of $0 \%, 3 \%$, and $11 \%$ in the ADV group. ${ }^{41,42}$ The data of antiviral resistance at 1, 2, and 3 years of LAM or ADV treatment are not available in previous studies with HBV-related HCC. ${ }^{6,7}$ However, the study $^{11}$ involving patients in the advanced stages of HBVrelated HCC reported significantly lower rates of antiviral resistance in the LAM group (3.4\% at 1 year) than among 
patients with chronic HBV infection but no HCC. Those authors ${ }^{11}$ suggested that the difference was due to the fact that they excluded the patients who died before experiencing antiviral resistance. Our patients generally enjoyed better prognosis than those in that study ${ }^{11}$ and we did not observe the same antiviral resistance mainly because their $\mathrm{HCC}$ was in very early or early stages. Antiviral resistance is caused mainly by mutations in the HBV polymerase gene that arise during nucleos $(\mathrm{t})$ ide analogue therapy and that render the polymerase less sensitive to the analogues. ${ }^{18}$ The emergence of such resistance may be followed by hepatitis flares, liver decompensation, and even death. However, these severe outcomes did not occur in our cohort, probably because patients were switched to entecavir immediately after antiviral resistance was detected.

We determined that the cost PPPD of antiviral medication was significantly higher in the LAM group than in the ADV group, partly because so many LAM patients suffered antiviral resistance and had to be switched onto more expensive entecavir therapy. In practice, the cost difference between LAM and ADV patients is likely to be even greater than what we measured because the emergence of antiviral resistance is associated with more frequent hospital visits, and more diagnostic and laboratory tests. ${ }^{43}$ Taking these additional costs into account, a Markov model-based study of patients with chronic $\mathrm{HBV}$ infection ${ }^{44}$ also found that long-term treatment with ADV was more cost-effective than with LAM, supporting our findings.

Several limitations of the current study must be considered. First, we did not diagnose antiviral resistance by measuring genotypic or phenotypic resistance; instead we relied only on virological and biochemical breakthrough. This may affect the accuracy of our results, because up to $30 \%$ of virological breakthrough in clinical trials is associated with medication noncompliance ${ }^{18}$ rather than resistant mutations. To reduce the risk of such error, we took care to diagnose patients as showing antiviral resistance only after excluding the possibility of medication noncompliance, tumor progression, drug hepatotoxicity, treatment-related hepatic damage, or other systemic infections that may influence HBV-DNA and ALT levels. The other limitations of our study are its retrospective observational design and its relatively small sample size. To compensate for these issues, we used propensity score matching and Cox regression analysis to analyze our data more thoroughly.

Overall and recurrence-free survival were comparable between the two groups, with or without propensity score matching. Cox regression analysis confirmed these results.
We conclude that ADV is as efficacious as LAM to treat HBV-related HCC after radical resection. At the same time, ADV may be more cost-effective than LAM therapy because it is associated with significantly lower rates of antiviral resistance, which requires more medical interventions and more expensive nucleos(t)ide analogue therapy. These findings, combined with those of a previous study comparing LAM and entecavir in HBV-related $\mathrm{HCC},{ }^{11}$ may help clinicians choose the most appropriate type of antiviral agent for newly diagnosed HBV-related HCC. These results may be especially helpful to developing countries, where ADV and LAM are frequently used and where health care budgets are limited. Further large prospective studies are needed to confirm the relative clinical efficacy of LAM and ADV in patients with HBV-related HCC, as well as to examine prognosis in the long term.

\section{Acknowledgments}

The first author (J-HZ) thanks professor Ming-Hua Zheng from Wenzhou Medical University for his kindly help of revision and suggestion of the manuscript. This work was supported by Guangxi Science and Technology Development Projects (14124003-4), the National Science and Technology Major Special Project (2012ZX10002010001009), Guangxi University of Science and Technology Research Projects (KY2015LX056), the Self-Raised Scientific Research Fund of the Ministry of Health of Guangxi Province (Z2016512, Z2015621, Z2015601, GZZC15-34, Z2014241), the Innovation Project of Guangxi Graduate Education (YCBZ2015030), and the Youth Science Foundation of Guangxi Medical University (GXMUYSF201302).

\section{Disclosure}

The authors report no conflicts of interest in this work.

\section{References}

1. Chen W, Zheng R, Baade PD, et al. Cancer statistics in China, 2015. CA Cancer J Clin. 2016;66(2):115-132.

2. Zhong JH, Ke Y, Gong WF, et al. Hepatic resection associated with good survival for selected patients with intermediate and advancedstage hepatocellular carcinoma. Ann Surg. 2014;260(2):329-340.

3. Forner A, Llovet JM, Bruix J. Hepatocellular carcinoma. Lancet. 2012;379(9822):1245-1255.

4. Zhong JH, Ma L, Li LQ. Postoperative therapy options for hepatocellular carcinoma. Scand J Gastroenterol. 2014;49(6):649-661.

5. Gong WF, Zhong JH, Xiang BD, Li LQ. Feasibility of combining adjuvant transarterial chemoembolization with nucleos(t)ide analog therapy for patients with HBV-associated hepatocellular carcinoma after hepatectomy. Mol Clin Oncol. 2016;5(1):3-6.

6. Yin J, Li N, Han Y, et al. Effect of antiviral treatment with nucleotide/ nucleoside analogs on postoperative prognosis of hepatitis B virus-related hepatocellular carcinoma: a two-stage longitudinal clinical study. J Clin Oncol. 2013;31(29):3647-3655. 
7. Huang G, Lau WY, Wang ZG, et al. Antiviral therapy improves postoperative survival in patients with hepatocellular carcinoma: a randomized controlled trial. Ann Surg. 2015;261(1):56-66.

8. Wu CY, Chen YJ, Ho HJ, et al. Association between nucleoside analogues and risk of hepatitis B virus-related hepatocellular carcinoma recurrence following liver resection. JAMA. 2012;308(18): $1906-1914$.

9. Wong JS, Wong GL, Tsoi KK, et al. Meta-analysis: the efficacy of anti-viral therapy in prevention of recurrence after curative treatment of chronic hepatitis B-related hepatocellular carcinoma. Aliment Pharmacol Ther. 2011;33(10):1104-1112.

10. Ke Y, Wang L, Li LQ, Zhong JH. Nucleos(t)ide analogues to treat hepatitis B virus-related hepatocellular carcinoma after radical resection. World J Hepatol. 2014;6(9):652-659.

11. Shin HS, Kim SU, Park JY, et al. Antiviral efficacy of lamivudine versus entecavir in patients with hepatitis B virus-related advanced hepatocellular carcinoma. J Gastroenterol Hepatol. 2012;27(9):1528-1534.

12. Kuzuya T, Katano Y, Kumada T, et al. Efficacy of antiviral therapy with lamivudine after initial treatment for hepatitis B virus-related hepatocellular carcinoma. J Gastroenterol Hepatol. 2007;22(11):1929-1935.

13. Kubo $\mathrm{S}$, Tanaka $\mathrm{H}$, Takemura $\mathrm{S}$, et al. Effects of lamivudine on outcome after liver resection for hepatocellular carcinoma in patients with active replication of hepatitis B virus. Hepatol Res. 2007;37(2):94-100.

14. Zhong JH, Xiang BD, Gong WF, et al. Comparison of long-term survival of patients with BCLC stage B hepatocellular carcinoma after liver resection or transarterial chemoembolization. PLoS One. 2013;8(7): e68193.

15. Zhong JH, Ke Y, Wang YY, Li LQ. Liver resection for patients with hepatocellular carcinoma and macrovascular invasion, multiple tumours, or portal hypertension. Gut. 2015;64(3):520-521.

16. Lok AS, McMahon BJ. Chronic hepatitis B. Hepatology. 2007;45(2): 507-539.

17. Wei Q, Xu X, Ling Q, Zheng S. Indefinite antiviral therapy may be required after surgical resection for hepatocellular carcinoma complicating chronic hepatitis B. J Res Med Sci. 2013;18(8):726-730.

18. Lok AS, McMahon BJ. Chronic hepatitis B: update 2009. Hepatology. 2009;50(3):661-662.

19. Ke Y, Ma L, You XM, et al. Antiviral therapy for hepatitis B virusrelated hepatocellular carcinoma after radical hepatectomy. Cancer Biol Med. 2013;10(3):158-164.

20. Universal currency converter. Available from: http://www.xe.com. Accessed September 27, 2014.

21. Ke Y, Zhong J, Guo Z, Liang Y, Li L, Xiang B. [Comparison liver resection with transarterial chemoembolization for Barcelona Clinic Liver Cancer stage B hepatocellular carcinoma patients on long-term survival after SPSS propensity score matching]. Zhonghua Yi Xue Za Zhi. 2014;94(10):747-750. Chinese.

22. Piao CY, Fujioka S, Iwasaki Y, et al. Lamivudine treatment in patients with HBV-related hepatocellular carcinoma - using an untreated, matched control cohort. Acta medica Okayama. 2005;59(5):217-224.

23. Zhong JH. Nucleos(t)ide analogue therapy for HBV-related HCC after hepatic resection: clinical benefits and unanswered questions. Tumour Biol. 2014;35(12):12779-12784.

24. Koda M, Nagahara T, Matono T, et al. Nucleotide analogs for patients with HBV-related hepatocellular carcinoma increase the survival rate through improved liver function. Intern Med. 2009;48(1):11-17.

25. Zhong JH, Ma L, Li LQ. Postoperative antiviral therapy with nucleos(t)ide analogs in patients with hepatitis B virus-related hepatocellular carcinoma. Ann Surg. Epub 2015 Oct 20.

26. Xie ZB, Zhu SL, Peng YC, et al. Postoperative hepatitis B virus reactivation and surgery-induced immunosuppression in patients with hepatitis B-related hepatocellular carcinoma. J Surg Oncol. 2015;112(6): 634-642.
27. Hung IF, Poon RT, Lai CL, Fung J, Fan ST, Yuen MF. Recurrence of hepatitis B-related hepatocellular carcinoma is associated with high viral load at the time of resection. Am J Gastroenterol. 2008;103(7): 1663-1673.

28. Chan AC, Chok KS, Yuen WK, et al. Impact of antiviral therapy on the survival of patients after major hepatectomy for hepatitis B virus-related hepatocellular carcinoma. Arch Surg. 2011;146(6):675-681.

29. Jiang JH, Xiang BD, Li LQ, Zhong JH. Postoperative antiviral therapy with nucleos $(\mathrm{t})$ ide analogs for patients with hepatitis $\mathrm{B}$ virusrelated hepatocellular carcinoma. Clin Res Hepatol Gastroenterol. 2016;40(3):e29-e30.

30. Su CW, Chiou YW, Tsai YH, et al. The influence of hepatitis B viral load and Pre-S deletion mutations on post-operative recurrence of hepatocellular carcinoma and the tertiary preventive effects by anti-viral therapy. PLoS One. 2013;8(6):e66457.

31. Xie ZB, Wang XB, Fu DL, et al. Postoperative hepatitis B virus reactivation in hepatitis $B$ virus-related hepatocellular carcinoma patients with hepatitis B virus DNA levels $<500$ copies $/ \mathrm{mL}$. Onco Targets Ther. 2016;9:4593-4603.

32. Liaw YF, Leung N, Kao JH, et al. Chronic hepatitis B guideline working party of the Asian-Pacific Association for the Study of the Liver. AsianPacific consensus statement on the management of chronic hepatitis B: a 2008 update. Hepatol Int. 2008;2(3):263-283.

33. Chinese Society of Hepatology and Chinese Society of Infectious Disease, Chinese Medical Association. The guideline of prevention and treatment for chronic hepatitis B (2010 version). Zhonghua Liu Xing Bing Xue Za Zhi. 2011;32(4):405-415.

34. European Association for the Study of the Liver. EASL clinical practice guidelines: management of chronic hepatitis B virus infection. $J$ Hepatol. 2012;57(1):167-185.

35. Keeffe EB, Dieterich DT, Han SH, et al. A treatment algorithm for the management of chronic hepatitis B virus infection in the United States: 2008 update. Clin Gastroenterol Hepatol. 2008;6(12):1315-1341.

36. Tong MJ, Pan CQ, Hann HW, et al. The management of chronic hepatitis B in Asian Americans. Dig Dis Sci. 2011;56(11):3143-3162.

37. He Z, Wang J, Liu K, et al. Randomized trial of lamivudine, adefovir, and the combination in $\mathrm{HBeAg}$-positive chronic hepatitis B. Clin Res Hepatol Gastroenterol. 2012;36(6):592-597.

38. Dienstag JL, Wei LJ, Xu D, Kreter B. Cross-study analysis of the relative efficacies of oral antiviral therapies for chronic hepatitis B infection in nucleoside-naive patients. Clin Drug Investig. 2007;27(1):35-49.

39. Lok AS, Lai CL, Leung N, et al. Long-term safety of lamivudine treatment in patients with chronic hepatitis B. Gastroenterology. 2003; 125(6):1714-1722.

40. Chang TT, Lai CL, Chien RN, et al. Four years of lamivudine treatment in Chinese patients with chronic hepatitis B. J Gastroenterol Hepatol. 2004;19(11):1276-1282.

41. Hadziyannis SJ, Tassopoulos NC, Heathcote EJ, et al; Adefovir Dipivoxil 438 Study Group. Long-term therapy with adefovir dipivoxil for $\mathrm{HBeAg-negative} \mathrm{chronic} \mathrm{hepatitis} \mathrm{B} \mathrm{for} \mathrm{up} \mathrm{to} 5$ years. Gastroenterology. 2006;131(6): 1743-1751.

42. Marcellin P, Chang TT, Lim SG, et al. Long-term efficacy and safety of adefovir dipivoxil for the treatment of hepatitis $\mathrm{B}$ e antigen-positive chronic hepatitis B. Hepatology. 2008;48(3):750-758.

43. Zhong JH, Li LQ, Wu LC. Lamivudine with or without adefovir dipivoxil for postoperative hepatocellular carcinoma. Cochrane Database Syst Rev. 2011;(12):CD008713.

44. Buti M, Casado MA, Calleja JL, et al. Cost-effectiveness analysis of lamivudine and adefovir dipivoxil in the treatment of patients with HBeAg-negative chronic hepatitis B. Aliment Pharmacol Ther. 2006; 23(3):409-419. 
OncoTargets and Therapy

\section{Publish your work in this journal}

OncoTargets and Therapy is an international, peer-reviewed, open access journal focusing on the pathological basis of all cancers, potential targets for therapy and treatment protocols employed to improve the management of cancer patients. The journal also focuses on the impact of management programs and new therapeutic agents and protocols on

patient perspectives such as quality of life, adherence and satisfaction. The manuscript management system is completely online and includes a very quick and fair peer-review system, which is all easy to use. Visit http://www.dovepress.com/testimonials.php to read real quotes from published authors.

Submit your manuscript here: http://www.dovepress.com/oncotargets-and-therapy-journal 